\title{
PENGARUH PENERAPAN UNDANG-UNDANG PROFESI AKUNTAN PUBLIK TERHADAP MINAT MAHASISWA MENJADI AKUNTAN PUBLIK (STUDI KASUS DI UNIVERSITAS INDONESIA DAN UNIVERSITAS TRISAKTI)
}

\author{
May Mulyaningsih \\ Fakultas Ekonomi Universitas Pakuan \\ E-mail:my_mlys@yahoo.com
}

\begin{abstract}
This research examines perception and motivation on public accountant influenced the interest of S1 Accounting students toward the profession in Indonesia due to Act No. 5 Year 2011 about Public Accountant. Population in this research are S1 Accounting students who are taking Auditing II subject in University of Indonesia (245 students) as representative of state university and Trisakti University (426 students) as representative of private university in Indonesia. Total sample students per university determined by using Slovin Formula with 5\% significant (error) level. Qualitatif data type that used in this research is primary data which is collected using survey method by distributing the quesioner. Independent variables (perception and motivation) also dependent variabel (interest) which are interval scale are measured using Likert scale. The validity test with product moment correlation formula and the realibility test with Spearman Brown formula are used for examining data quality. The classic assumption tests which are consist of normality test, multicolinearity test, autocorrelation test and heteroscedastisity test are used for testing all hypothesis. Hypothesis also tested by using regression with double regression analysis equation. Results show that perception and motivation on public accountant, simultaneously and partially, influenced the interest of S1 Accounting students in University of Indonesia and Trisakti University toward public accountant.
\end{abstract}

Keywords: Perception, Motivation, Interest, Public Accountant, Act No. 5 Year 2011 about Public Accountant

\section{PENDAHULUAN}

Tahun 2012 di Indonesia terjadi konvergensi Pernyataan Standar Akuntansi Keuangan (PSAK) dengan International Financial Reporting Standards (IFRS). Hal ini memberi dampak pada semakin meningkatnya kebutuhan akan jasa Akuntan Publik (AP) di Indonesia, yang pada akhirnya dapat mengakibatkan krisis keterbatasan Sumber Daya Manusia (SDM) atas AP di Indonesia.

Pusat Pembinaan Akuntan dan Jasa Penilai (PPAJP) membagi auditor di Indonesia menjadi dua kelompok berdasarkan ukuran KAP yaitu Big-4 dan Non Big-4. Gambar 1 menunjukkan bahwa berdasarkan ukurannya KAP Non Big-4 dapat dirinci lagi menjadi empat kelompok yaitu KAP berukuran sedang (medium), berukuran kecil (small), berukuran sangat kecil (very small) dan perorangan (solo). Pengelompokan kelima KAP tersebut dapat dilihat antara lain dari jumlah karyawan, kapasitas menerima besarnya dan banyaknya auditee, serta besarnya fee jasa audit yang diterima. 


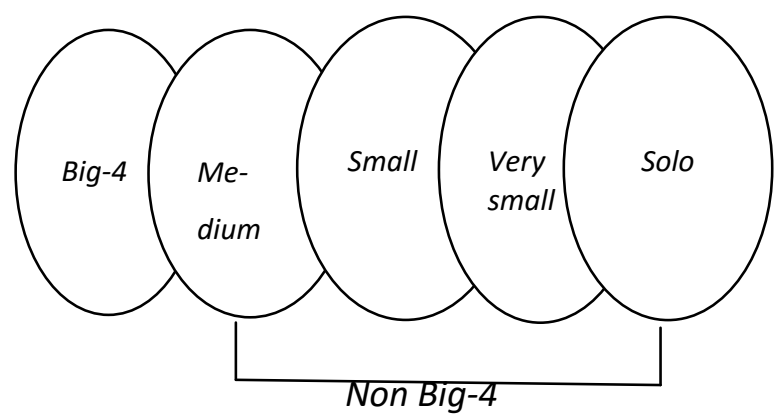

Sumber: PPAJP yang diolah, 2012.

Gambar 1. Struktur Pasar Jasa Audit di Indonesia tahun 2012

Tabel 1 menunjukan rasio AP beregister yang berhak mendirikan KAP terhadap jumlah KAP adalah 1,100:408 = 3 (angka pembulatan). Hal tersebut dapat diartikan bahwa setiap 3 orang AP beregister memiliki 1 KAP. Kondisi ini menunjukan bahwa SDM AP beregister yang dimiliki setiap KAP di Indonesia masih kurang.

Tabel 1. Jumlah AP Beregister, KAP, Cabang KAP, dan KAP Kerjasama Dengan KAPA/OAA di Indonesia Tahun 2011

\begin{tabular}{|l|l|}
\hline URAIAN & $\mathbf{2 0 1 1}$ \\
\hline AP beregister & 1,100 \\
\hline KAP & 408 \\
\hline Cabang KAP & 108 \\
\hline KAP kerjasama dengan KAPA/OAA & 48 \\
\hline
\end{tabular}

Sumber: PPAJP yang diolah, 2012.

Gambar 2 memperlihatkan semakin muda kelompok usia AP beregister semakin sedikit jumlahnya. Hal ini menunjukan adanya krisis keterbatasan SDM AP beregister di Indonesia khususnya yang bekerja di KAP. Bila AP beregister generasi usia tua sudah kurang produktif bekerja maka jumlah generasi usia muda penggantinya kurang mencukupi.

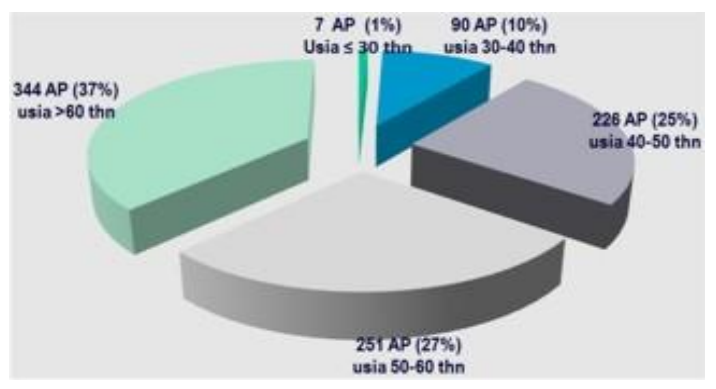

Sumber: PPAJP, 2012. Gambar 2. Struktur Usia AP Beregister Dalam KAP di Indonesia tahun 2012

Tingginya tingkat turnover AP di KAP setiap tahun membuktikan kurangnya minat menjadi AP beregister. Ada dua hal utama penyebab banyaknya auditor junior yang resign dari KAP meskipun baru setahun bekerja. Pertama yaitu ritme kerja yang cepat dan meluapnya beban kerja dalam rangka mengejar rentetan dead line membuat mereka mengalami stres dan terserang penyakit tipes. Kedua yaitu trend bahwa profesi AP adalah batu loncatan para fresh graduate untuk memulai awal karir mereka.

Minat para calon AP di Indonesia terutama mahasiswa diharapkan dapat meningkat dengan adanya peraturan tentang profesi AP yaitu Undang-Undang (UU) No. 5 tahun 2011 tentang Akuntan Publik dan UU No. 34 tahun 1954 tentang Pemakaian Gelar Akuntan Publik. Gambar 3 menjelaskan sebelum adanya UU No. 5 tahun 2011 hanya lulusan S1 Akuntansi yang berhak menjadi AP beregister, sedangkan setelah adanya UU ini lulusan non S1 Akuntansi juga berhak menjadi AP beregister.

JIAFE (Jurnal Ilmiah Akuntansi Fakultas Ekonomi)

Volume 2 No. 2 Tahun 2016, Hal. 28-38 


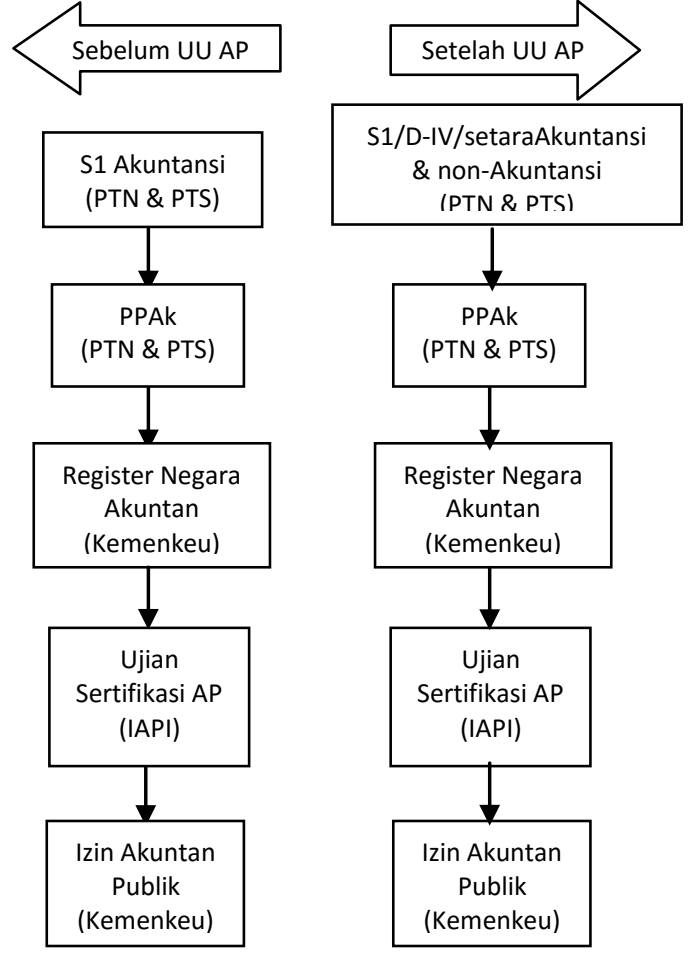

Sumber: PPAJP yang diolah, 2012.

Gambar 3. Proses Menjadi AP

Sebelum dan setelah UU No. 5 tahun 2011 tentang AP.

\section{Perumusan Masalah}

Identifikasi masalah dalam penelitian ini adalah sebagai berikut:

1. Apakah persepsi atas profesi AP mempengaruhi minat mahasiswa S1 Akuntansi terhadap profesi AP?

2. Apakah motivasi atas profesi AP mempengaruhi minat mahasiswa S1 Akuntansi terhadap profesi AP?

\section{Tujuan Penelitian}

Tujuan dari penelitian ini adalah untuk menjawab permasalahan penelitian yaitu:

1. Mengetahui apakah persepsi atas profesi AP mempengaruhi minat mahasiswa S1 Akuntansi terhadap profesi AP.

2. Mengetahui apakah motivasi atas profesi AP mempengaruhi minat mahasiswa S1 Akuntansi terhadap profesi AP.

\section{KAJIAN LITERATUR \\ Persepsi}

Persepsi merupakan proses kognitif yang dipergunakan seseorang untuk menafsirkan dan memahami dunia sekitarnya (Bawono dkk, 2006).

\section{Motivasi}

Menurut Hellriegel et al. (2001) motivasi adalah kebutuhan individu untuk berperilaku dalam suatu cara tertentu yang menyebabkan orang memiliki beberapa tata cara untuk meraih tujuan organisasi (Subramaniam dan Ramachandran, 2012).

\section{Minat}

Minat adalah ketertarikan pada sesuatu hal tanpa paksaan yang timbul akibat partisipasi, pengetahuan dan kebiasaan (Slameto, 2001 dalam Mahmud, 2008).

\section{Kerangka Penelitian}

\begin{tabular}{|c|c|}
\hline Persepsi & $\begin{array}{c}\text { Minat Mahasiswa S1 Akuntansi } \\
\text { atas Profesi Akuntan Publik } \\
\text { di Indonesia Terkait } \\
\text { UU No. } 5 \text { tahun } 2011\end{array}$ \\
\hline
\end{tabular}

Gambar 4. Kerangka Penelitian

Berdasarkan pengajuan variabel-variabel independen dan variabel dependen dalam Gambar 4 maka diajukan dua hipotesis di bawah ini.

H1: Persepsi atas profesi AP mempengaruhi minat mahasiswa S1 Akuntansi terhadap profesi AP.

H2: Motivasi atas profesi AP mempengaruhi minat mahasiswa S1 Akuntansi terhadap profesi AP.

\section{METODOLOGI PENELITIAN}

Penelitian ini menggunakan jenis penelitian uji hipotesis dengan metode penelitian uji hubungan sebab-akibat. Objek dalam penelitian ini adalah persepsi dan motivasi sebagai variabel independen dan 
minat sebagai variabel dependen. Tujuan penelitian ini adalah untuk menguji pengaruh dua variabel independen yaitu persepsi (X1) dan motivasi (X2) terhadap satu variabel dependen yaitu minat $(\mathrm{Y})$ dengan menggunakan metode statistik analisis regresi berganda.

\section{Populasi}

Populasi dalam penelitian ini adalah mahasiswa program S1 Akuntansi yang sedang mengambil mata kuliah Audit II, yaitu mahasiswa semester 6 di Universitas Indonesia dan mahasiswa semester 5 di Universitas Trisakti. Universitas Indonesia dipilih sebagai perwakilan untuk PTN dan Universitas Trisakti dipilih sebagai perwakilan untuk PTS, keduanya dianggap mewakili karena berlokasi di Jakarta yang memiliki mahasiswa terbanyak di Indonesia.

\section{Teknik Pengambilan Sampel}

Teknik pengambilan sampel dilakukan dengan metode pemilihan sampel nonprobabilitas yaitu pemilihan sampel bertujuan (purposive sampling) berdasarkan pertimbangan (judgement sampling). Jumlah sampel mahasiswa setiap Universitas ditentukan dengan menerapkan Rumus Slovin (Umar, 2004). Jenis data kualitatif yang digunakan adalah data primer (primary data).

\section{Teknik Pengumpulan Data}

Teknik pengumpulan data menggunakan metode survei melalui penyebaran kuesioner ke Universitas Indonesia dan Universitas Trisakti dalam jangka waktu 1 bulan.

\section{Pengukuran Variabel Penelitian}

Variabel-variabel independen (persepsi dan motivasi) dan variabel dependen (minat) yang merupakan skala interval diukur menggunakan skala Likert (Indriantoro dan Supomo, 2002) dengan angka penilaian 1 sampai dengan 5 .

Tabel 2. Operasionalisasi Variabel

\begin{tabular}{|l|l|l|}
\hline VARIABEL & \multicolumn{1}{|c|}{ REFERENSI } & SKALA \\
\hline Persepsi & $\begin{array}{l}\text { Bawono, dkk } \\
\text { (2006); Pekdemir, }\end{array}$ & Interval \\
\hline
\end{tabular}

\begin{tabular}{|c|c|c|}
\hline & $\begin{array}{l}\text { et.al (2013); Aditya } \\
\text { (2010); Fitriany dan } \\
\text { Yulianti (2007); } \\
\text { Yuliantir dan } \\
\text { Fitriyani (2006); } \\
\text { Ranie dan Rizal } \\
\text { (2012); Mustapha } \\
\text { and Hassan (2012) }\end{array}$ & \\
\hline Motivasi & $\begin{array}{l}\text { Subramaniam and } \\
\text { Ramachandran } \\
\text { (2012); } \\
\text { Setyawardani } \\
\text { (2009); Sugahara } \\
\text { and Boland (2006); } \\
\text { Kunartinah dan } \\
\text { Widiatmoko } \\
\text { (2003); Kurnia } \\
\text { (2009); Suyatmin, } \\
\text { dkk (2008); Miller, } \\
\text { et.al (1998) }\end{array}$ & Interval \\
\hline Minat & $\begin{array}{l}\text { Linda dan Muda } \\
\text { (2011); Lisnasari } \\
\text { dan Fitriany (2008); } \\
\text { Mahmud (2008); } \\
\text { Suranta dan } \\
\text { Syafiqurrahman } \\
\text { (2006); Widiastuti } \\
\text { dan Suryaningsum } \\
\text { (2005) }\end{array}$ & Interval \\
\hline
\end{tabular}

Sumber: Hasil Penelitian (2013 (Diolah)

\section{Metode Analisis Data}

Pengujian kualitas data atas data kualitatif yang digunakan dalam penelitian ini menggunakan uji validitas dan uji reliabilitas, perhitungan pengujian dilakukan memakai software Microsoft program Excel 2010. Uji validitas menggunakan rumus korelasi product moment (Singarimbun, 1995), sedangkan uji reliabilitas menggunakan rumus Spearman Brown (Prayitno, 2010).

\section{Pengujian Hipotesis}

Untuk menguji kriteria hipotesis diterima atau ditolak, maka dilakukan uji asumsi klasik yang terdiri atas empat pengujian yaitu uji normalitas, uji multikolinearitas, uji autokorelasi, dan uji heteroskedastisitas. Uji Normalitas dilakukan dengan dua cara yaitu

JIAFE (Jurnal Ilmiah Akuntansi Fakultas Ekonomi)

Volume 2 No. 2 Tahun 2016, Hal. 28-38 
melihat grafik histogram dan normal probability plot (Prayitno, 2010). Uji multikolinearitas dilakukan dengan melihat nilai inflation factor (VIF) (Prayitno, 2010). Uji autokorelasi dilakukan menggunakan DurbinWatson (Prayitno, 2010). Uji heteroskedastisitas dilakukan menggunakan uji Spearman's rho (Prayitno, 2010).

Setelah data diyakini valid dan reliabel kemudian dilakukan pengujian hipotesis yang telah dirumuskan. Penelitian ini menggunakan uji regresi sebagai uji hipotesis dengan menggunakan persamaan analisis regresi berganda (Sugiyono, 2003).

\section{HASIL PENELITIAN DAN PEMBAHASAN}

Berdasarkan data mahasiswa dari sekretaris jurusan akuntansi S1 di masingmasing universitas, diketahui populasi responden untuk Universitas Indonesia (UI) sebanyak 245 mahasiswa dan untuk Universitas Trisakti sebanyak 426 mahasiswa. Dari data tersebut, sampel responden dihitung menggunakan rumus Slovin sehingga dapat diketahui sampel responden sebanyak 152 mahasiswa untuk Universitas Indonesia dan 206 mahasiswa untuk Universitas Trisakti. Kuesioner dibagikan kepada seluruh sampel tersebut (100\%). Hasil penentuan sampel dapat dilihat dalam Tabel 3 di bawah ini.

Tabel 3. Penentuan Sampel

\begin{tabular}{|l|r|r|}
\hline UNIVERSITAS & N & N \\
\hline Universitas Indonesia & 245 & 152 \\
\hline Universitas Trisakti & 426 & 206 \\
\hline Jumlah & $\mathbf{6 7 1}$ & $\mathbf{3 5 8}$ \\
\hline
\end{tabular}

Sumber: Hasil Penelitian, 2013 (Diolah).

Keterangan:

$\mathrm{N}=$ Jumlah populasi

$\mathrm{n}=$ Jumlah sampel

\section{Hasil Pengolahan Data}

Pengujian kualitas data atas data kualitatif yang digunakan dalam penelitian ini menggunakan uji validitas dan uji reliabilitas, perhitungan pengujian dilakukan memakai software Microsoft program Excel 2010. Uji validitas menggunakan rumus korelasi product moment (Singarimbun, 1995). Item instrumen dianggap valid jika koefisien korelasi $(r)>0,3$ (Singarimbun, 1995). Dari hasil pengujian validitas dalam tabel 4 , tabel 5 , dan tabel 6 terbukti bahwa semua pernyataan kuesioner valid.

Tabel 4.Hasil Uji Validitas Butir Pernyataan Persepsi Untuk UI dan Universitas Trisakti

\begin{tabular}{|c|c|c|}
\hline $\begin{array}{c}\text { BUTIR } \\
\text { PERTANYAAN }\end{array}$ & ANGKA $r$ & KETERANGAN \\
\hline \multicolumn{3}{|c|}{ A. Persepsi atas profesi auditor } \\
\hline 1 & 0,476 & Valid \\
\hline 2 & 0,630 & Valid \\
\hline 3 & 0,552 & Valid \\
\hline 4 & 0,531 & Valid \\
\hline
\end{tabular}

B. Persepsi atas jenjang karir yang luas pada profesi auditor

\begin{tabular}{|c|c|c|}
\hline 1 & 0,671 & Valid \\
\hline 2 & 0,571 & Valid \\
\hline 3 & 0,367 & Valid \\
\hline
\end{tabular}

C.Persepsi atas pembelajaran berkelanjutan/ pengetahuan

\begin{tabular}{|c|c|c|}
\hline 1 & 0,549 & Valid \\
\hline 2 & 0,446 & Valid \\
\hline 3 & 0,614 & Valid \\
\hline 4 & 0,565 & Valid \\
\hline
\end{tabular}

Sumber: Hasil Penelitian, 2013 (Diolah).

Tabel 5. Hasil Uji Validitas Butir Pernyataan Motivasi Untuk UI dan Universitas Trisakti

\begin{tabular}{|c|c|c|}
\hline $\begin{array}{c}\text { BUTIR } \\
\text { PERTANYAAN }\end{array}$ & ANGKA $r$ & KETERANGAN \\
\hline \multicolumn{3}{|c|}{ A. Motivasi untuk menjadi auditor } \\
\hline 1 & 0,637 & Valid \\
\hline 2 & 0,670 & Valid \\
\hline 3 & 0,673 & Valid \\
\hline 4 & 0,581 & Valid \\
\hline \multicolumn{3}{|c|}{ B. Motivasi atas jenjang karir yang luas } \\
\hline 1 & & Valid \\
\hline 2 & 0,462 & Valid \\
\hline 3 & 0,563 & Valid \\
\hline 4 & 0,577 & Valid \\
\hline \multicolumn{3}{|c|}{$\begin{array}{l}\text { C.Motivasi atas pembelajaran berkelanjutan/ } \\
\text { pengetahuan }\end{array}$} \\
\hline 1 & 0,661 & Valid \\
\hline 2 & 0,634 & Valid \\
\hline
\end{tabular}

JIAFE (Jurnal Ilmiah Akuntansi Fakultas Ekonomi) Volume 2 No. 2 Tahun 2016, Hal. 28-38 


\begin{tabular}{|c|c|c|}
\hline 3 & 0,591 & Valid \\
\hline 4 & 0,575 & Valid \\
\hline 5 & 0,521 & Valid \\
\hline
\end{tabular}

Sumber: Hasil Penelitian, 2013 (Diolah).

Tabel 6.Hasil Uji Validitas Butir Pernyataan Minat Untuk UI dan Universitas Trisakti

\begin{tabular}{|c|c|c|}
\hline $\begin{array}{c}\text { BUTIR } \\
\text { PERTANYAAN }\end{array}$ & ANGKA $r$ & KETERANGAN \\
\hline A. & \\
\hline
\end{tabular}

A. Minat terhadap informasi atas UU No. 5 Tahun 2011 tentang Akuntan Publik

\begin{tabular}{|c|c|c|}
\hline 1 & 0,729 & Valid \\
\hline 2 & 0,733 & Valid \\
\hline 3 & 0,738 & Valid \\
\hline
\end{tabular}

B. Minat terhadap profesi Akuntan Publik di Indonesia

\begin{tabular}{|c|c|c|}
\hline 1 & 0,699 & Valid \\
\hline 2 & 0,585 & Valid \\
\hline 3 & 0,594 & Valid \\
\hline 4 & 0,541 & Valid \\
\hline 5 & 0,578 & Valid \\
\hline 6 & 0,532 & Valid \\
\hline 7 & 0,575 & Valid \\
\hline
\end{tabular}

Sumber: Hasil Penelitian, 2013 (Diolah).

Sedangkan uji reliabilitas menggunakan rumus Spearman Brown (Prayitno, 2010). Nilai koefisien reliabilitas dianggap cukup baik bila $r_{11}>0,7$ dan dianggap baik bila $r_{11}>0,8$ (Prayitno, 2010). Dari hasil pengujian reliabilitas dalam Tabel 7 terbukti bahwa semua pernyataan kuesioner reliabel.

Tabel 7.Hasil Uji Reliabilitas Untuk UI dan Universitas Trisakti

\begin{tabular}{|c|c|c|}
\hline VARIABEL & ANGKA $\boldsymbol{r}$ & KETERANGAN \\
\hline Persepsi & 0,826 & Reliabel \\
\hline Motivasi & 0,891 & Reliabel \\
\hline Minat & 0,915 & Reliabel \\
\hline
\end{tabular}

Sumber: Hasil Penelitian, 2013 (Diolah).

Untuk menguji kriteria hipotesis diterima atau ditolak, maka dilakukan uji asumsi klasik yang terdiri atas empat pengujian yaitu uji normalitas, uji multikolinearitas, uji autokorelasi dan uji heteroskedastisitas. Uji normalitas dilakukan dengan dua cara yaitu melihat grafik histogram dan normal probability plot (Prayitno, 2010) untuk UI dan Universitas Trisakti melalui SPSS versi 21.

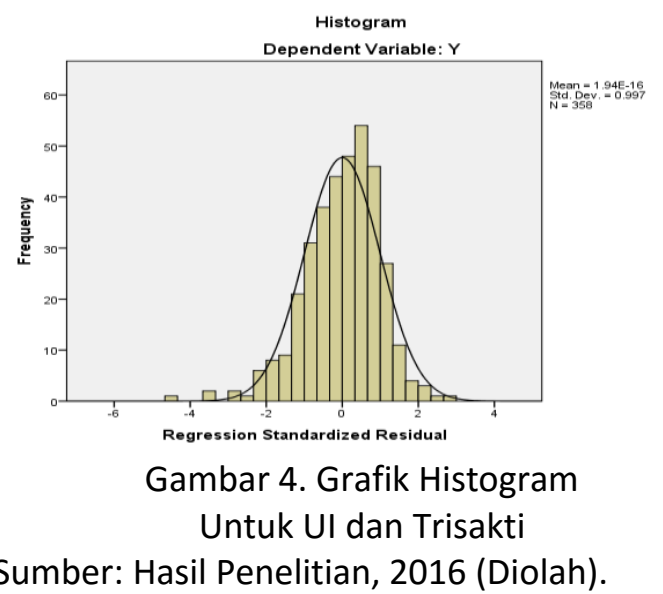

Dari hasil pengujian menggunakan grafik histogram dan normal probability plot dapat dinyatakan bahwa tidak terjadi masalah normalitas. Dalam Gambar 4 terlihat bahwa histogram menunjukkan pola distribusi normal (yang tidak miring ke kiri maupun ke kanan). Sedangkan grafik dalam Gambar 5 memperlihatkan bahwa titik-titik menyebar di sekitar garis dan mengikuti garis diagonal, sehingga nilai residual tersebut telah normal.

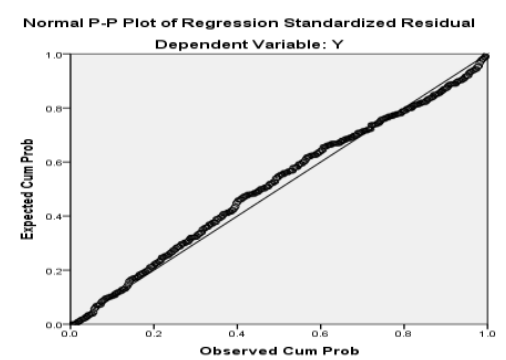

Gambar 5. Normal Probability Plot

Untuk UI dan Universitas Trisakti Sumber: Hasil Penelitian, 2016 (Diolah).

Uji multikolinearitas dilakukan dengan melihat nilai inflation factor (VIF) (Prayitno, 2010). Suatu variabel dikatakan tidak memiliki multikolinearitas dengan variabel independen lainnya jika nilai $\mathrm{VIF}<5$. Berdasarkan hasil uji multikolinearitas dengan SPSS versi 21 untuk UI dan Universitas Trisakti dapat dinyatakan bahwa dalam model regresi tidak ditemukan adanya masalah multikolinearitas. Dalam Tabel 8 terlihat bahwa VIF persepsi 1,459 dan VIF

JIAFE (Jurnal Ilmiah Akuntansi Fakultas Ekonomi)

Volume 2 No. 2 Tahun 2016, Hal. 28-38 
motivasi 1,459 dimana nilai VIF masing-masing variabel $<5$.

Tabel 8. Hasil Uji Multikolinearitas Untuk UI dan Universitas Trisakti

\begin{tabular}{|c|c|c|c|c|c|}
\hline \multirow[t]{2}{*}{ Model } & \multicolumn{2}{|c|}{$\begin{array}{c}\text { Unstandardized } \\
\text { Coefficients }\end{array}$} & \multirow{2}{*}{$\begin{array}{l}\text { Standardized } \\
\text { Coefficients } \\
\text { Beta }\end{array}$} & \multicolumn{2}{|c|}{$\begin{array}{c}\text { Collinearity } \\
\text { Statistics }\end{array}$} \\
\hline & B & $\begin{array}{l}\text { Std. } \\
\text { Error }\end{array}$ & & $\begin{array}{l}\text { Tole- } \\
\text { rance }\end{array}$ & VIF \\
\hline (Constant) & 7,857 & 3,089 & & & \\
\hline Persepsi & ,252 & ,083 & 175 & 685 & 1,459 \\
\hline Motivasi & ,332 & ,058 & ,326 & ,685 & 1,459 \\
\hline
\end{tabular}

Sumber: Hasil Penelitian, 2016 (Diolah).

Uji autokorelasi dilakukan menggunakan Durbin-Watson (Prayitno, 2010) dengan ketentuan:

a. Jika $\mathrm{d}<\mathrm{dl}$ atau $\mathrm{d}>(4-\mathrm{dl})$, maka Ho ditolak yang berarti terdapat autokorelasi.

b. Jika $d u<d<(4-d u)$, maka Ho diterima yang berarti tidak ada autokorelasi.

c. Jika $\mathrm{dl}<\mathrm{d}<\mathrm{du}$ atau (4-du) $<\mathrm{d}<$ (4-dl), maka tidak ada kesimpulan yang pasti.

Nilai du dan dl diperoleh dari tabel statistik Durbin-Watson yang bergantung pada banyaknya observasi dan banyaknya variabel independen. Berdasarkan hasil uji autokorelasi dengan SPSS versi 21 untuk UI dan Universitas Trisakti dapat dinyatakan bahwa tidak terjadi masalah autokorelasi. Dalam Tabel 9 diperoleh nilai tabel Durbin-Watson untuk $\mathrm{K}=4$ dan $\mathrm{n}=$ 360 yaitu $\mathrm{dl}=181029 ; \mathrm{du}=1,84389 ; 4-\mathrm{dl}=$ 2,$190 ; 4-d u=2,156$. Karena nilai DurbinWatson hitung $(d=1,965)$ terletak antara nilai $\mathrm{du}=1,84389$ dan 4-du = 2,156 maka dapat dinyatakan bahwa tidak terjadi masalah autokorelasi.
Tabel 9. Hasil Uji Autokorelasi Untuk UI dan Universitas Trisakti

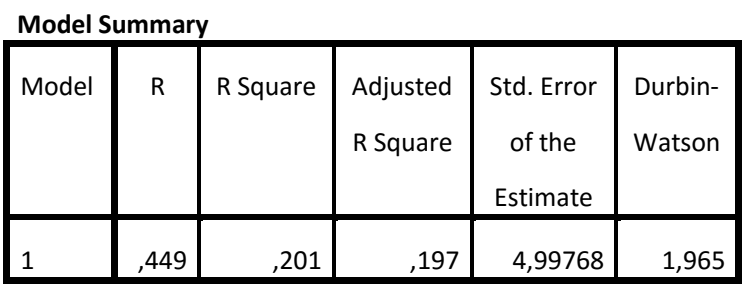

Sumber: Hasil Penelitian, 2016 (Diolah).

Uji heteroskedastisitas dilakukan menggunakan uji Spearman's rho (Prayitno, 2010), yaitu mengkorelasikan nilai residual (unstandardized residual) dengan masingmasing variabel independen. Agar syarat regresi dapat terpenuhi, maka nilai signifikansi korelasi harus $>0,05$, artinya nilai residual dengan nilai masing-masing variabel independen tidak ada korelasi. Berdasarkan hasil uji heteroskedastisitas dengan SPSS versi 21 untuk UI dan Universitas Trisakti dalam Gambar 10, dapat dinyatakan bahwa dalam model regresi tidak ditemukan adanya masalah heteroskedastisitas.

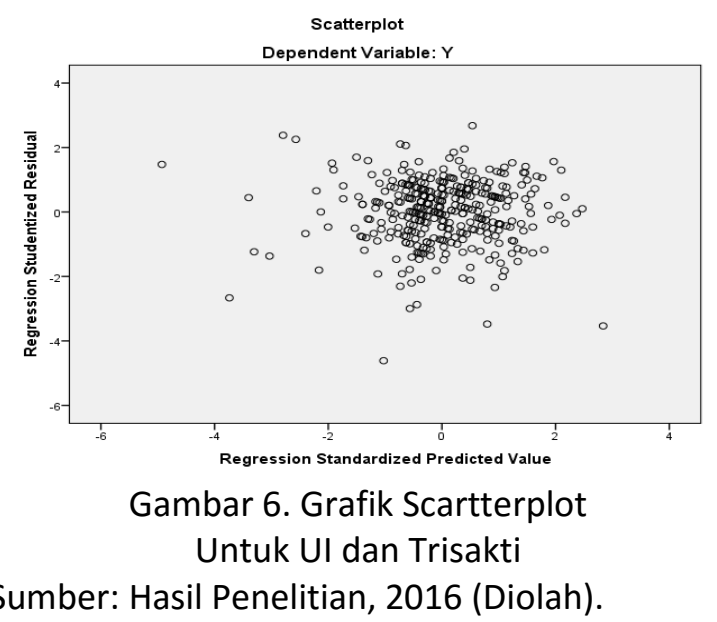

Setelah data diyakini valid dan reliabel kemudian dilakukan pengujian hipotesis yang telah dirumuskan yaitu:

H1: Persepsi atas profesi AP mempengaruhi minat mahasiswa S1 Akuntansi terhadap profesi AP. 
H2 : Motivasi atas profesi AP mempengaruhi minat mahasiswa S1 Akuntansi terhadap profesi AP.

Jika dilihat secara simultan (bersamasama), maka kedua variabel independen (persepsi dan motivasi) memiliki pengaruh yang signifikan terhadap variabel dependen (minat). Hal ini dibuktikan berdasarkan pengujian dengan uji $\mathrm{F}$ yang diperlihatkan dalam Tabel 10. Nilai signifikan untuk $F$ sebesar 0,000 yaitu $<0,05$ yang berarti persepsi dan motivasi secara bersama-sama memiliki pengaruh yang signifikan terhadap minat.

Tabel 10. Hasil Uji Hipotesis Secara Simultan Untuk UI dan Trisakti

\begin{tabular}{|l|r|r|r|r|r|}
\hline \multicolumn{1}{|c|}{ Model } & $\begin{array}{c}\text { Sum of } \\
\text { Squares }\end{array}$ & Df & $\begin{array}{c}\text { Mean } \\
\text { Square }\end{array}$ & F & Sig. \\
\hline Regression & 2233,290 & 2 & 1116,645 & 44,707 &, 000 \\
Residual & 8866,768 & 355 & 24,977 & & \\
Total & 11100,059 & 357 & & & \\
\hline
\end{tabular}

Sumber: Hasil Penelitian, 2016 (Diolah).

Berdasarkan hasil pengolahan regresi dengan SPSS versi 21 untuk UI dan Universitas Trisakti seperti yang terlihat dalam Tabel 11, diperoleh hasil bahwa persamaan regresi adalah:

Minat $=7,857+0,252$ Persepsi $+0,332$ Motivasi

Artinya persepsi mempengaruhi minat secara positif sebesar 0,252 kali dan motivasi mempengaruhi minat secara positif sebesar 0,332 kali. Selain itu konstanta mempengaruhi minat secara positif sebesar 7,857 kali apabila persepsi dan motivasi tidak ada (nol).

Jika dilihat secara parsial (terpisah), maka kedua variabel independen (persepsi dan motivasi) memiliki pengaruh signifikan terhadap variabel dependen (minat). Hal ini dibuktikan berdasarkan pengujian dengan uji $t$ yang diperlihatkan dalam Tabel 10 . Nilai signifikansi persepsi sebesar 0,002 yaitu $<0,05$ yang berarti persepsi memiliki pengaruh signifikan terhadap minat. Nilai signifikansi motivasi sebesar 0,000 yaitu $<0,05$ yang berarti motivasi memiliki pengaruh signifikan terhadap minat.

Tabel 11. Hasil Uji Hipotesis Secara Parsial Untuk UI dan Trisakti

\begin{tabular}{|c|c|c|c|c|c|}
\hline \multicolumn{6}{|c|}{ Coefficients } \\
\hline \multirow[t]{2}{*}{ Model } & \multicolumn{2}{|c|}{$\begin{array}{c}\text { Unstandardized } \\
\text { Coefficients }\end{array}$} & $\begin{array}{l}\text { Standardized } \\
\text { Coefficients }\end{array}$ & $\mathrm{t}$ & Sig. \\
\hline & B & $\begin{array}{l}\text { Std. } \\
\text { Error }\end{array}$ & Beta & & \\
\hline (Constant) & 7,857 & 3,089 & & 2,544 & ,011 \\
\hline Persepsi & ,252 & ,083 & ,175 & 3,051 & ,002 \\
\hline Motivasi & ,332 & ,058 & ,326 & 5,697 & , 000 \\
\hline
\end{tabular}

Sumber: Hasil Penelitian, 2016 (Diolah).

\section{KESIMPULAN DAN SARAN}

\section{Kesimpulan}

Penelitian ini dilakukan untuk mengetahui apakah persepsi dan motivasi atas profesi AP mempengaruhi minat mahasiswa S1 Akuntansi terhadap profesi AP di Indonesia terkait UU No. 5 tahun 2011 tentang Akuntan Publik. Dari pengaruh variabel independen (persepsi dan motivasi) terhadap variabel dependen (minat), hasil penelitian terbagi menjadi dua kondisi yaitu bila dilihat secara simultan (bersama-sama) dan bila dilihat secara parsial (terpisah).

Bila dilihat secara simultan (bersamasama), baik persepsi dan motivasi atas profesi AP mempengaruhi minat mahasiswa S1 Akuntansi Universitas Indonesia (mahasiswa PTN) terhadap profesi AP di Indonesia. Hasil yang sama juga berlaku untuk mahasiswa Universitas Trisakti (mahasiswa PTS). Dengan demikian bila dilihat secara simultan (bersamasama), tidak terdapat perbedaan pengaruh atas persepsi dan motivasi terhadap minat diantara mahasiswa PTN dengan mahasiswa PTS.

Bila dilihat secara parsial (terpisah), persepsi mahasiswa Universitas Indonesia (mahasiswa PTN) dan mahasiswa Universitas Trisakti (mahasiswa PTS) atas profesi AP 
mempengaruhi minat mahasiswa S1 Akuntansi terhadap profesi AP di Indonesia. Dengan demikian tidak ada perbedaan pengaruh atas persepsi terhadap minat diantara mahasiswa PTN dengan mahasiswa PTS. Juga motivasi mahasiswa Universitas Indonesia (mahasiswa PTN) dan mahasiswa Universitas Trisakti (mahasiswa PTS) atas profesi AP mempengaruhi minat mahasiswa S1 Akuntansi terhadap profesi AP di Indonesia. Dengan demikian tidak ada perbedaan pengaruh atas motivasi terhadap minat diantara mahasiswa PTN dengan mahasiswa PTS.

\section{Manfaat Penelitian}

Hasil penelitian ini diharapkan dapat memberikan kontribusi bagi akademisi dan praktisi di Indonesia juga bagi penelitian selanjutnya. Bagi akademisi, penelitian ini diharapkan dapat membantu dunia pendidikan di Indonesia untuk meningkatkan kualitas calon akuntan profesional sehingga memberikan nilai tambah bagi profesinya. Perguruan Tinggi (PT) disarankan memperbanyak mata kuliah yang relevan dengan dunia kerja dan praktek audit yang memadai sehingga lulusan mahasiswa S1 Akuntansi dapat masuk ke dunia kerja dengan mudah.

Bagi praktisi, penelitian ini diharapkan dapat membantu pemerintah Indonesia pada umumnya dalam rangka menanggulangi kemungkinan krisis keterbatasan SDM AP. Pemerintah disarankan mendukung berdirinya KAP kecil dan memantau perkembangannya karena KAP kecil dapat membuka lapangan kerja bagi lulusan mahasiswa S1 Akuntansi dan mengurangi pengangguran dari kalangan lulusan mahasiswa S1 Akuntansi. Berkurangnya pengangguran akan mengurangi angka kemiskinan nasional, selain itu potensi generasi muda diharapkan mampu mengembangkan Republik Indonesia sehingga mampu bersaing dalam kancah internasional.

Selain itu bagi praktisi, penelitian ini diharapkan dapat membantu profesi akuntan publik di Indonesia pada khususnya dalam rangka menanggulangi kemungkinan krisis keterbatasan SDM AP. KAP disarankan memperbanyak training bagi auditor junior yang umumnya mahasiswa S1 Akuntansi yang baru lulus agar menjadi pekerja profesional yang berkualitas.

Bagi penelitian selanjutnya, penelitian ini diharapkan dapat memberikan dasar bagi penelitian selanjutnya dengan mencoba variabel-variabel independen lainnya yang diduga mempengaruhi minat. Serta penambahan responden baik dari sisi geografis maupun demografis seperti sampel pada PTN dan PTS lainnya diluar Jakarta. Perluasan sampel juga mencakup mahasiswa-mahasiswa lulusan program S2, S3 dan PPAk. Terkait dengan UU No. 5 tahun 2011 tentang Akuntan Publik bahwa alumni non-akuntansi dapat menjadi AP, hal tersebut tidak dilakukan dalam penelitian ini sehingga dapat menjadi fokus bagi penelitian selanjutnya.

\section{Keterbatasan Penelitian}

Penelitian ini memiliki tiga keterbatasan. Pertama, penelitian ini hanya mengkaji dua variabel independen yang diduga mempengaruhi minat yaitu persepsi dan motivasi. Untuk penelitian selanjutnya direkomendasikan untuk menambahkan beberapa variabel independen lain yang diduga mempengaruhi minat.

Kedua, responden yang dijadikan sampel dalam penelitian ini terbatas pada mahasiswa program S1 Akuntansi yang sedang mengambil mata kuliah Audit II di Universitas Indonesia sebagai perwakilan untuk PTN dan Universitas Trisakti sebagai perwakilan untuk PTS di Indonesia. Responden ini mungkin kurang mewakili opini mahasiswa di luar Jakarta. Untuk penelitian selanjutnya direkomendasikan untuk memperluas responden yaitu dengan mengambil sampel dari PTN dan PTS lainnya di luar Jakarta.

Ketiga, responden yang dijadikan sampel dalam penelitian ini terbatas pada mahasiswa program S1 Akuntansi. Responden ini mungkin kurang mewakili opini mahasiswa akuntansi yang lain. Untuk penelitian selanjutnya direkomendasikan untuk memperluas sampel yaitu dengan melibatkan para mahasiswa 
lulusan program S2, S3 dan PPAk sebagai responden penelitian.

\section{DAFTAR PUSTAKA}

Aditya, E. M., 2010. Perbedaan Persepsi Antara Mahasiswa Senior dan Junior Mengenai Profesi Akuntan Pada Program S1 Reguler dan S1 Transfer PTS X. Fokus Ekonomi, Vol. 5 No. 2 Desember 2010: 95-103.

Bawono, I. R.; M. Novelsyah;danA. Lutfia,2006.Persepsi Mahasiswa Jurusan Akuntansi Reguler dan Non Reguler Tentang Pendidikan Profesi Akuntansi.JAAI, Vol. 10 No. 2, Desember 2006: 185-193.

Fitriany dan Yulianti, 2007.Perbedaan Persepsi Antara Mahasiswa Senior dan Junior Mengenai Profesi Akuntan Pada Program S1 Reguler, S1 Ekstensi dan Program Diploma 3".Simposium Nasional Akuntansi X.26-28 Juli 2007,Unhas Makassar, Indonesia.

Indriantoro, N. dan B. Supomo, 2002.Metodologi Penelitian Bisnis Untuk Akuntansi dan Manajemen, Edisi ke-1. Yogyakarta: BPFE Yogyakarta.

Kunartinah dan J. Widiatmoko, 2003.Perilaku Mahasiswa Akuntansi di STIE Stikubank Semarang dan Faktor-faktor Yang Mempengaruhi Pemilihan Karir Sebagai Akuntan Publik.Jurnal Bisnis dan Ekonomi, September 2003: 1-19.

Kurnia, 2009.Perbedaan Persepsi Tentang Karier di Kantor Akuntan Publik Antara Mahasiswa dan Staf Kantor Akuntan Publik.Ekuitas, Vol. 13, No. 2, Juni 2009: 199-218.

Linda dan I.Muda, 2011.Pengaruh Pengetahuan Akuntansi dan Motivasi Terhadap Minat Mahasiswa Akuntansi Perguruan Tinggi Negeri dan Swasta di Propinsi Nangroe Aceh Darussalam Untuk Mengikuti Pendidikan Profesi Akuntansi (PPAk).Jurnal Keuangan \& Bisnis, Vol. 3, No. 2, Juli 2011: 133-143.

Lisnasari dan Fitriany, 2008. Faktor-faktor Yang Mempengaruhi Minat Mahasiswa Akuntansi Untuk Mengikuti Pendidikan
Profesi Akuntansi (PPAk), Studi Empiris di Universitas Indonesia. The $2^{\text {nd }}$ Accounting Conference $1^{\text {st }}$ Doctoral Colloquium, and Accounting Workshop.4-5 November 2008, Depok, Indonesia.

Machfoedz, M., 1998. Survey Minat Mahasiswa Untuk Mengikuti Ujian Sertifikasi Akuntan Publik (USAP). Jurnal Ekonomi dan Bisnis Indonesia, Vol. 3, No. 4, 1998: 110-124.

Mahmud, A., 2008. Pengaruh Motivasi Terhadap Minat Mahasiswa Untuk Mengikuti Pendidikan Profesi Akuntan. Jurnal Pendidikan Ekonomi, Vol. 3, No. 1 Pebruari 2008: 21-44.

Miller, J; J. Bligh; I. Stanley; and A. Al Shehri, 1998. Motivation and Continuation of Professional Development.British Journal of General Practice, July 1998: 14291432.

Mulyaningsih, M., 2014. Analisis Minat Mahasiswa S1 Akuntansi Untuk Berprofesi Sebagai Akuntan Publik di Indonesia Setelah Penerapan UU No. 5 Tahun 2011 Tentang Akuntan Publik.Tesis.Program Magister Akuntansi Universitas Trisakti, Jakarta.

Mustapha, M. and M. H. Abu Hassan, 2012.Accounting Students' Perception on Pursuing Professional Examination.International Journal of Education, Vol. 4, No. 4, 2012: 1-15.

Pekdemir, I.; R. Pekdemir; and Y. Sen, 2013. A Comparative Study on The Business School Students' Perceptions on The Professional Accountancy of Turkey. Accounting and Management Information Systems, Vol. 12, No. 1, 2013: 39-60.

Prayitno, D., 2010.Paham Analisa Statistik Data dengan SPSS. Jakarta: Mediakom.

Ranie, Z. A. dan M.Rizal, 2012. Persepsi Mahasiswa Akuntansi Mengenai Lingkungan Kerja Auditor Terhadap Pilihan Karirnya Sebagai Auditor (Studi Empiris Pada Mahasiswa Akuntansi Pada Perguruan Tinggi di Sumut). Jurnal IImiah Pendidikan Tinggi, Vol. 5, No. 3, Desember 2012: 123-134. 
Setyawardani, L., 2009. Persepsi Mahasiswa Senior dan Junior Terhadap Profesi Akuntan.Ekuitas, Vol. 13, No. 1, Maret 2009: 82-100.

Singarimbun, M., 1995.Metodologi Penelitian Survei. Jakarta: PT Pustaka.

Subramaniam, R. and J.Ramachandran, 2012. An Empirical Study on The Choice of Accounting and Auditing As A Career, An Evidence From Malaysia. South East Asian Journal of Contemporary Business, Economics and Law, Vol. 1, 2012: 92-100.

Sugahara, S. and G.Boland, 2006. Perceptions of The Certified Public Accountants by Accounting and Non-Accounting Tertiary Students In Japan. Asian Review of Accounting, Vol. 14 No. 1, February 2006: 149-167.

Sugiyono, 2003.Statistika Untuk Penelitian. Bandung: CV Alfabeta.

Suranta, S. dan M.Syafiqurrahman, 2006.Pengaruh Motivasi Terhadap Minat Mahasiswa Untuk Mengikuti Pendidikan Profesi Akuntansi (PPAk) di Karesidenan Surakarta.Empirika, Vol. 1, No. 1, Juni 2006: 111-116.

Suyatmin;M. A. Aris; dan Wahyono, 2008. Persepsi Mahasiswa Akuntansi Terhadap Lingkungan Kerja Akuntan Publik. Jurnal Akuntansi dan Keuangan, Vol. 7, No. 2, September 2008: 131-143.

Widiastuti, S. W. dan S.Suryaningsum, 2005. Pengaruh Motivasi Terhadap Minat Mahasiswa Akuntansi Untuk Mengikuti Pendidikan Profesi Akuntansi (PPAk). Jurnal Akuntansi \& Manajemen, Vol. 16, Th. 1, April 2005: 67-77.

Yulianti dan Fitriyani, 2006. Persepsi Mahasiswa Akuntansi Mengenai Profesionalisme Akuntan. Economic Business \& Accounting Review (EBAR), Edisi II, April 2006: 134-144. 